Anaesthesist 2013 - 62:146-146

DOI 10.1007/s00101-012-2127-9

Online publiziert: 3. Februar 2013

๑) Springer-Verlag Berlin Heidelberg 2013

\title{
Neues Hilfsmittel für die Dosierung von Notfallmedikamenten im Kindesalter
}

vation, diese deutschsprachige, an Vorgaben des „Pediatric Advanced Life Support“ (PALS) und des „European Pediatric Life Support“ (EPLS) adaptierte Version herauszugeben. Medikamentendosierungen und passende Ausrüstung entstammen zumeist dem in Ihrem Beitrag in Tab. 1 erwähnten eBroselow/ArtemisSystem. Durch diese Zusammenarbeit mit Jim Broselow und den Artemis-Entwicklern besitzt Kindersicher all die von Ihnen erwähnten Vorteile des „color-coding “. Die standardisierte, längenbasierte Farbcodierung mithilfe des zugehörigen Maßbands kann somit auch zur Gewichtsabschätzung für andere pädiatrische Dosierungshilfen genutzt werden (z. B. GNOM; - Abb. 1, 2). Farbcode sowie Ausrüstung und Dosierungen sind natürlich kompatibel mit den eBroselow/ Artemis-Apps und Onlineanwendungen sowie farbcodierten Taschensystemen und Narkosewagen.

Um die Informationen für die 11 Längenbereiche detaillierter und lesbarer dar- zustellen, finden sich bei Kindersicher die Vitalparameter, passende Ausrüstung und Medikamente auf je einer farbcodierten Seite in einem Infoflip-Büchlein. Durch Angabe standardisierter Verdünnungen werden Dosierungs- und Rechenfehler eliminiert: Die passende Medikamentendosis wird gleich in Millilitern angegeben. So kann das Kindersicher-System helfen, Fehler zu vermeiden. Es schafft Ruhe und Sicherheit bei der professionellen Versorgung von Kindernotfällen.

Auf der Homepage http://www.kindersicher.me finden Sie weitere Informationen.

\section{Korrespondenzadresse}

\section{T.O. Zugck}

Sophie Dethleffs Str. 17, 25746 Heide Info@kindersicher.me

Interessenkonflikt. Der korrespondierende Autor weist auf folgende Beziehungen hin: T. Zugck ist Autor und Hersteller des Kindersicher-Systems, das auch von ihm vertrieben wird.

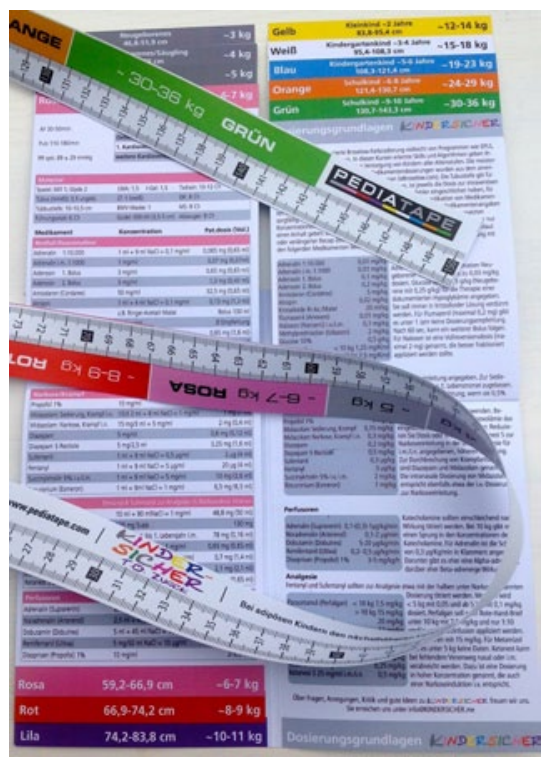

Abb. $1 \Delta$ System „Kindersicher": Infoflip und Maßband
Abb. $2 \nabla_{\text {"Kinder- }}$ sicher" am Patienten

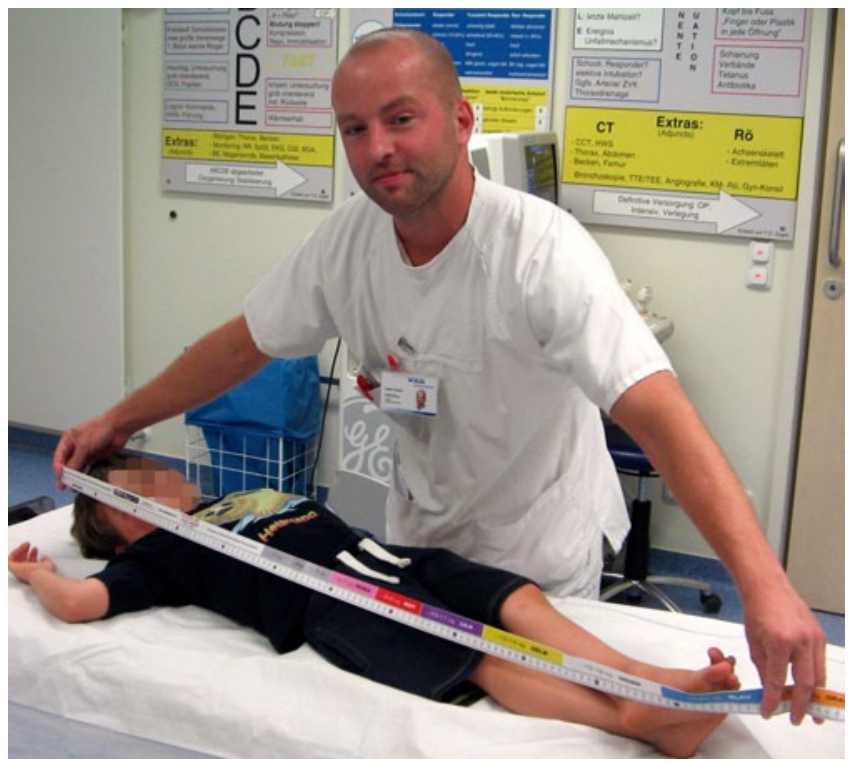

